\title{
Truffle Market Evolution: An Application of the Delphi Method
}

\author{
Daniel Oliach 1,2,3,*(D), Enrico Vidale ${ }^{4}$, Anton Brenko ${ }^{5}$, Olivia Marois ${ }^{6}$, Nicola Andrighetto ${ }^{7}$, Kalliopi Stara ${ }^{8} \mathbb{D}$, \\ Juan Martínez de Aragón ${ }^{1}$, Carlos Colinas ${ }^{1,3}$ and José Antonio Bonet ${ }^{3,9}$ (D)
}

1 Forest Science and Technology Centre of Catalonia (CTFC), Crta. Sant Llorenç de Morunys km 2, 25280 Solsona, Spain; mtzda@ctfc.cat (J.M.d.A.); carlos.colinas@udl.cat (C.C.)

2 Forest Bioengineering Solutions S. A., Crta. Sant Llorenç de Morunys km 2, 25280 Solsona, Spain

3 Department of Crop and Forest Sciences, University of Lleida, Av. Rovira Roure, 191, 25198 Lleida, Spain; jantonio.bonet@udl.cat

4 Dipartimento TESAF, University of Padua, Viale Dell’Università 16, 35020 Legnaro, PD, Italy; enrico.vidale@unipd.it

5 Croatian Forest Research Institute, Cvjetno Naselje 41, 10450 Jastrebarsko, Croatia; antonb@sumins.hr

6 CNPF, Délégation Auvergne-Rhône-Alpes, Site de Saint-Baldoph, 40 Rue du Terraillet, 73190 Saint-Baldoph, France; olivia.marois@crpf.fr

7 ETIFOR, Piazza A. De Gasperi 41, 35131 Padova, Italy; nicola.andrighetto@etifor.com

8 Laboratory of Ecology, Department of Biological Applications and Technology, University of Ioannina, 45110 Ioannina, Greece; kstara@uoi.gr

9 Joint Research Unit CTFC-Agrotecnio, Avda. Rovira Roure, 191, 25198 Lleida, Spain

* Correspondence: daniel.oliach@ctfc.cat

check for

updates

Citation: Oliach, D.; Vidale, E.; Brenko, A.; Marois, O.; Andrighetto, N.; Stara, K.; Martínez de Aragón, J.; Colinas, C.; Bonet, J.A. Truffle Market Evolution: An Application of the Delphi Method. Forests 2021, 12, 1174. https://doi.org/10.3390/f12091174

Academic Editors: José G. Borges, Davide M. Pettenella, Yu Wei and Emin Z. Başkent

Received: 2 August 2021

Accepted: 26 August 2021

Published: 30 August 2021

Publisher's Note: MDPI stays neutral with regard to jurisdictional claims in published maps and institutional affiliations.

Copyright: (c) 2021 by the authors. Licensee MDPI, Basel, Switzerland. This article is an open access article distributed under the terms and conditions of the Creative Commons Attribution (CC BY) license (https:/ / creativecommons.org/licenses/by/ $4.0 /)$.
Abstract: Background: The objective of this study was to analyze the current situation of the truffle sector in the main producing countries of the Mediterranean area. Additionally, we identified the challenges for the future and the priority actions to develop the truffle sector in the region. Methods: We used a Delphi process approach, and we selected a total of 17 expert panelists in different positions within the supply chain of the target countries (Spain, France, Italy, Croatia, and Greece). Results: The results obtained allowed us to have a complete description of the current truffle supply chain. We confirmed an evolution of the sector due to the cultivation success of several Tuber species. The maturity of the sector has produced shifts in the roles that form the traditional truffle supply chain operators. We confirmed the trend of a decrease of collectors that hunt truffles in the wild and sell to small travelling buyers, whilst truffle hunters that collect for farmers and specialty wholesalers are emerging. However, a trend of truffle price decrease in the last few years has alerted the sector. Conclusions: As production increases due to truffle cultivation, it will be necessary to promote truffle consumption. We identified actions to develop the truffle sector: (a) strengthen the link between truffles, tourism, and gastronomy; (b) increase the effort at European level for the recognition of truffle production, helping to develop truffle culture and marketing; (c) increase the awareness and consumption of truffles among consumers; and (d) develop tourism workshops for truffle farmers.

Keywords: non-wood forest products; Tuber; supply-chain analysis; SWOT; truffle tourism

\section{Introduction}

Wild edible fungi play an important ecological role in nature, and their fruitbodies are among the most valuable non-wood forest products, with great potential for trade expansion [1]. Up to 268 fungal species are authorized to be marketed in Europe, but only 60 of them can be cultivated [2]. Truffles belonging to the Tuber genus are among the few and most successful attempts to cultivate edible mycorrhizal fungi [3]. Truffles are the fruiting bodies of hypogeous ascomycete fungi which form ectomycorrhizal associations with gymnosperm or angiosperm trees or shrubs [4]. At least 180 species of Tuber have been reported around the world [5], even if only about 13 have any commercial interest [6]. Nowadays, some of these species, such as Tuber melanosporum Vittad., Tuber aestivum Vittad., Tuber borchii Vittad. and Tuber brumale Vittad., are routinely and successfully cultivated [7]. 
Tuber magnatum Picco cultivation has been difficult in contrast to the previously mentioned species, but recently a successful attempt at its cultivation in France, outside the natural range of this species, also demonstrates the feasibility of its cultivation [8]. T. brumale plantations may also be economically beneficial, but because it was considered as a contaminating fungus in T. melanosporum plantations, its cultivation is less developed $[9,10]$. T. borchii cultivation has become widespread mainly in Italy and, more recently, also in New Zealand, Australia, and North and South America [11]. However, in spite of the new alternatives for truffle species cultivation, the most cultivated species of the genus Tuber still are T. melanosporum and T. aestivum, mainly in the Mediterranean area.

The unique and intense aroma of truffles make them one of the most expensive foods in the world [12]. Tuber magnatum is the most famous and valued truffle, with prices ranging from EUR 1000-1500 per kg due its particular and attractive aroma [8,13]. T. aestivum is the most common species across Europe but less appreciated, with prices from EUR 25-70 per kg in Spain [14] to EUR 200-600 per kg in Switzerland [15]. T. brumale has a characteristic musky odor and is the less appreciated of the winter truffles in Europe [12], with prices ranging from EUR 60-120 per kg in Spain [14]. T. borchii, can reach prices of up to EUR 200-250 per kg in Italy when the season of other species of the genus Tuber is bad [14], and is becoming increasingly popular in the market [16]. Among them, T. melanosporum is one of the most appreciated fungi in the market and its hunting in the wild and cultivation is important for rural livelihoods and landscapes in southern Europe [6,17,18]. In Spain, the average price paid to wild collectors and growers of T. melanosporum during the last decade has ranged from EUR 170 to 550 per $\mathrm{kg}$ [14], whereas prices of selected truffles in international markets reach the EUR 2000-4000 per kg range [6].

T. melanosporum is naturally harvested in Europe, mainly in the Mediterranean areas of Spain, France, and Italy [6]. Historically, truffles were collected from the wild, but the success in inoculating host trees with T. melanosporum in the 1970s [19] opened the door to the species cultivation in managed plantations. The commercialization of inoculated seedlings brought the expansion of black truffle cultivation that nowadays sources the larger part of marketed truffles, while the quantity of truffles collected in the wild has been falling since the last century [20]. This decline of wild truffle production is likely due to socioeconomic factors such as changes in forest use and rural abandonment [20]. Climate change has also been proposed to explain this decline of wild truffle production in Europe [21,22].

In recent decades, T. melanosporum cultivation has expanded from the Mediterranean to all Mediterranean-climate regions around the world and beyond. Thanks to inoculated seedlings, the research advances and the economical profits obtained with the black truffle crop T. melanosporum has been introduced in Australia, New Zealand, USA, South Africa, Chile, Morocco, Greece, Turkey, and China, among others. Despite the decline of wild production, the amounts in the market have increased during the last years due to cultivation efforts. Spain is leading the world production of T. melanosporum and its cultivation, with a mean annual production of 47 tons per year during the period 2013-2018 [14], having more than 20,000 hectares currently planted and around 80,100, and 104 collected tons during the last three seasons $(2018 / 19,2019 / 20$, and 2020/21, respectively) [23]. France and Italy have produced an average of 43 and 19 tons per year, respectively, during the period 2013-2018 [14], however, there has not been the same increase during the last three seasons as in Spain. Australia, with 11 tons per year [24], and Chile, with 1.3 tons in 2020 [25], are also becoming players in the black truffle world arena.

In France, Italy, Spain, and Australia, truffles are an emerging 'global industry' [26]. The economic activity of the truffle sector generates tens of millions of euros annually [27-30]. Besides direct benefits, black truffle production promotes other activities, such as truffle tourism [18], production of seedlings mycorrhized with T. melanosporum, production of truffle products, technical consulting [31]; it stimulates interdisciplinary research [32], and increases land value in rural areas [31]. However, the increase of global black truffle production in a very short time, especially in Europe, has brought a certain fatigue to 
the European market. We expect further increases of T. melanosporum production in other countries within the framework of a global market, which should imply a risk of change of truffle gravity center from the Mediterranean to other areas, as well as changes in the market operator roles.

During the last decades, the European market has undergone changes due to the cultivation of truffles. New producers have appeared in a traditional sector linked to wild production, and new business opportunities have emerged through online sales, giving more visibility to the truffle. This new player, the truffle grower, in addition to selling fresh truffles to intermediaries or retailers in the country, exports truffles directly to the final consumer or to retailers worldwide.

The objective of this study is to analyze the current situation of the truffle sector in the main Mediterranean producing countries, the different challenges that the sector is facing, and the priority actions to guarantee the resilience of the truffle sector in the region. The analysis covers the main truffle producing countries (Spain, France, Italy, Croatia) and emerging Mediterranean countries such as Greece. The analysis has been performed through a Delphi survey carried out in the frame of the INCREdible project (www.incredibleforest.net (accessed on 1 August 2021)) that collected the opinion of the supply chain operators. The collected information can be valuable for the operators of the entire supply chain, including academia and policy makers, who usually only have a fragmented or partial vision of the truffle sector.

\section{Materials and Methods}

The truffle sectorial analysis has been developed through a Delphi survey methodology that encompasses the selection of an expert panel which is requested to individually answer a questionnaire in a limited number of rounds. The Delphi survey technique is based on the idea that the opinions from a structured group of individuals is more accurate, and thus more powerful, than those from unstructured groups [33]. The method has demonstrated its robustness in market trends analysis as well as in sectorial forecasting [34].

The Delphi process started with the selection of the Truffle Expert Panel, which included members from the countries participating in the INCREdible project (Spain, France, Italy, Croatia, and Greece), but also representatives from international organizations.

A total of 17 expert panelists actively participated in the survey with an unbalanced number of participants per country, due to the different development of the truffle supply chains in the targeted countries. The respondents were requested to answer only the questions on those topics in which they had expertise.

The panelists were selected so they belonged to different positions in the supply chain so that we would see their different approaches to any given topic. Therefore, producers (wild collectors and growers), processors, but also forest managers or technicians, and experts from technological centers, associations, and academia took part in the process.

The questionnaire was divided into four sections: (1) description of the supply chain, (2) SWOT analysis of the Strengths, Weaknesses, Opportunities, and Threats of the sector, (3) future challenges of the sector and, finally, (4), prioritized actions to be taken in order to increase the resilience of the sector. The initial list of sector challenges as well as the prioritized actions were obtained by crossing the identified SWOT statements.

The expert panelists in the first round of the questionnaire were asked to identify and weight the relevance of several statements about the truffle sector, based on the knowledge collected during activities developed in the INCREDIBLE project. Such activities included three international workshops which were held in Spain, Italy, and Croatia between the years 2018 and 2019 with the participation of 164 attendants (www.incredibleforest.net (accessed on 1 August 2021)). The questions were mainly quantitative (weighting was between 0 (no relevance) and 10 (utmost relevance)), but qualitative questions were also included. The outcomes and opinions collected in the first round were analyzed to reshape the questionnaire for a second round, after refining or dividing some statements and adding new topics proposed by some of the experts for the consideration of the entire panel. 
This second questionnaire was individually addressed. Each expert panelist received a comparison of his/her own marks with the average score of all panelists for each statement. The individual expert was requested to confirm his/her own marks in the first round or to modify it according to the opinion of the rest of the expert panelists, looking for possible harmonization or consensus-without neglecting possible regional or supply-chain position related differences in their points of view. During the whole process, experts' identities and performance were treated individually and there was no possibility to trace the information they provided. All the individual results were analyzed and used in an aggregate way.

To describe the truffle supply chain, a first attempt was conformed during previous INCREdible events with different experts and agents of the truffle supply chain. The selected experts received a proposal with associate text that intended to describe the truffle supply chain and they were requested to confirm or refine their validity. The suggested improvements collected during the first round were also submitted to the consideration of all the panelists during the second round. Finally, we reached a consensus to define the truffle supply chain with the panelists.

The obtained results are presented as an average of the ratings assigned by the experts and the standard deviation of all the experts' answers.

\section{Results}

\subsection{Description of the Supply Chain}

Truffles are collected in wild truffle beds in forests or in truffle orchards. The owner and the hunter are often the same person in a truffle orchard, but the figure of the professional truffle hunter, who harvests plantations for a fee, has emerged in recent times. In the case of wild truffle beds, the situation was the opposite. The truffle hunters are not usually the forest owners, and they hunt in unregulated areas or in private areas by purchasing the right to collect, or directly without permission in public or privately owned forest areas. Truffles are revealed with the help of dogs and are extracted from the soil with specific tools. Once the truffle is collected, the wild and cultivated production merges without distinguishing the origin. The truffles may be directly consumed as a fresh product or processed (preserved food) as an ingredient for manufactured food products. The direct sale from producers to consumers exists, but more frequently sales are made through the industry and/or retailers. The general roadmap from producer to consumer includes the truffle intermediary or trading companies (wholesalers) and the retailers (Figure 1). Tourism, including truffle hunting and truffle consumption in restaurants or cooking in situ is relatively recent, and it is much more developed in some areas of the Mediterranean than in others.

The expert panelists also contributed to forecast the future of the truffle supply chain in the next decade in Mediterranean Europe (Italy, Spain, France, Croatia, and Greece). The main results obtained were (i) the supply chain will not change a lot in the next decade and the only expected variations would be the impact of some stakeholders and their weights, although one expert stated that changes could be expected at national but not at the international level; (ii) truffle producers will develop their own marketing network in order to sell directly on the retail markets or using online trading, although it seems not to be a homogeneous trend in all the Mediterranean area, expecting less changes in France; (iii) more online buying and selling of fresh and processed products is expected, as well as more consumption at country level and increase in truffles supply worldwide and yearround; (iv) with the increasing offer worldwide, there will be a price drop, if the market dimension remains the same, but it will be stabilized if the demand keeps the current global growing trend. In this context, local producers will seek to distinguish themselves through an environmentally friendly product or to develop territorial designations; (v) the decrease of wild production will continue due to forest and land management abandonment and climatic extreme events, such as long droughts, strong winds or heavy rain storms, although this trend will not be the same for all truffle species (climate change will differentially affect truffle species occurrence) [24]. With less consensus than the previous ones, we 
highlight: (vi) It is expected to have global competition, and thus truffles could lose their uniqueness (Table 1).

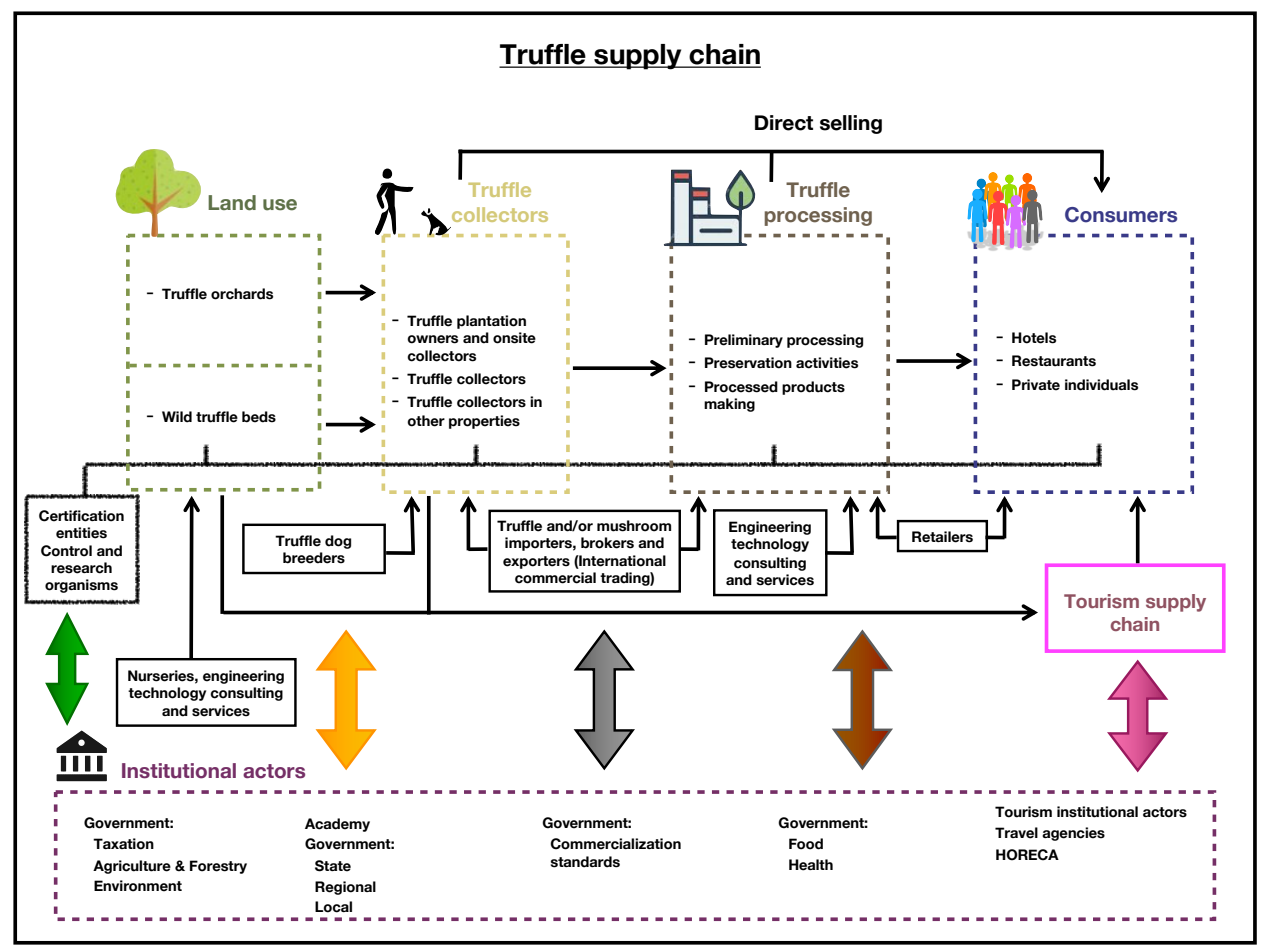

Figure 1. Description of the truffle supply chain developed during the INCREdible events and validated by the truffle panel experts.

\subsection{SWOT Analysis of the Truffle Sector}

The SWOT analysis is divided into analysis of Strengths (S), Weaknesses (W), Opportunities $(\mathrm{O})$, and Threats $(\mathrm{T})$ (Table 2). We identified the five most important strengths of the truffle sector (Table 2). The top ranked strengths rely on the recognized value of truffles as a gastronomic product as well as their increasing use in cuisine. The mystery and the adventure that is also associated with truffle hunting (hidden product located with the help of a dog) is also positively perceived by expert panelists. The compatibility of truffle cultivation with environmental conservation and the leadership of Mediterranean truffle business companies obtained marks of 8.2 and 8.4 (out of 10), respectively, and are also among the top strengths of the truffle sector. In contrast, the experts within the supply chain were not so optimistic about the positive truffle prices evolution pattern (5.2 out of 10). Similarly, the experts questioned the high profitability of truffle cultivation (6.3 out of 10), although this perception is dependent on the property size and the country (Italy $=5.8 \pm 1.6$; France $=5.6 \pm 1.4$; Spain $=8.4 \pm 0.7)$. The full set of statements rated by the experts can be found in Table S1.

The most relevant weaknesses of the truffle sector are mainly related to the gap period between the establishment of the truffle plantation and the regular truffle harvesting that can be achieved after 7-10 years (Table 2). The truffle farmers complain against having to contribute to agricultural social security without having any economic return for the first years. In spite of the recognized value of the truffle by the consumers, the panelists highly rated (8.6 out of 10) the fact that consumers are not informed enough about the potential uses of truffles and truffle products as a culinary ingredient. The lack of knowledge also emerged as a truffle sector weakness. It relates to different aspects of the truffle sector, such as the imprecise management techniques for truffle cultivation (8.2 out of 10), the still existing knowledge gaps about the truffle life cycle (7.4 out of 10), or the lack of official market statistics (7.2 out of 10). The sector also identifies as a weakness the lack of professionalism (8.4 out of 10), and the poor cooperation within the supply chain operators 
(7.6 out of 10). Other identified weaknesses were less rated probably due to the intrinsic nature of truffle ecology (Table S2). Among them, the high truffle production variability due to weather variability was scored with 7.8 (out of 10), especially in the case of T. borchii (9.8), T. melanosporum (9.6), and T. magnatum (8.1) species, whilst the continuous decrease of wild truffle production was rated with 7.3 (out of 10). On the contrary, other weaknesses have not been considered as relevant as the previous ones. The lack of continuing education focused on producers and technicians and the lack of technical support for truffle farmers were both scored with 6.4 (out of 10).

Table 1. Forecast of the future of the truffle supply chain by the expert panel. The table summarizes the total number of responses (agree/disagree/not answer) of the 17 panelists to the question: How the supply chain will change in the next decade in Mediterranean Europe (Italy, Spain, France, Croatia, Greece)?

\begin{tabular}{|c|c|c|c|}
\hline Statement & Yes, I Agree & Not, I Disagree & I Don't Know \\
\hline $\begin{array}{l}\text { Supply chain will not change a lot in the future, the only thing that } \\
\text { could change is the impact of some stakeholders and their weights }\end{array}$ & 14 & 2 & 1 \\
\hline $\begin{array}{l}\text { Truffle producers will become more powerful actors, developing } \\
\text { more and more their own marketing network, selling directly on the } \\
\text { retail market, or selling online }\end{array}$ & 14 & 3 & 0 \\
\hline $\begin{array}{c}\text { It is expected to have global competition, and thus truffles will lose } \\
\text { their uniqueness }\end{array}$ & 11 & 6 & 0 \\
\hline $\begin{array}{c}\text { The increasing offer worldwide, will bring (generally) a price drop. } \\
\text { In this context, local producers will seek to distinguish themselves } \\
\text { through environmental quality of their production or to develop } \\
\text { territorial designations }\end{array}$ & 13 & 4 & 0 \\
\hline $\begin{array}{l}\text { There will be a decrease in wild production whilst more plantations } \\
\text { in Southern Mediterranean Europe will be established, but without } \\
\text { affecting the supply chain }\end{array}$ & 10 & 6 & 1 \\
\hline $\begin{array}{l}\text { Some intermediaries will disappear, due to the better organization of } \\
\text { the owners and hunters }\end{array}$ & 12 & 4 & 1 \\
\hline $\begin{array}{l}\text { More online buying and selling of fresh and processed products. } \\
\text { More local consumption and increase in truffles supply worldwide } \\
\text { and year-round }\end{array}$ & 16 & 0 & 1 \\
\hline $\begin{array}{l}\text { It is expected to have an important increase of both demand and offer } \\
\text { (more slowly) in areas of Greece }\end{array}$ & 12 & 0 & 2 \\
\hline $\begin{array}{l}\text { It is expected to have a more complex supply chain, with more truffle } \\
\text { species that have been somewhat sidelined until now in the market }\end{array}$ & 11 & 5 & 1 \\
\hline
\end{tabular}

The truffle operators display truffle-based tourism activities as an opportunity if the truffle sector links such a product with gastronomy ( 8.9 out of 10) as well as with other services to develop multiproduct and multisession tourism (e.g., wines, olive oil, pates, lavender, cold cut meats, cheeses) and the "terroir" concept (8.4 out of 10) (Table 2). In spite of the increase of truffle plantations surface, the expert panelists still consider as an opportunity the growth potential of truffle cultivation in the Mediterranean countries (8.4 out of 10), maybe due to the fact that truffle demand is still increasing (8.3 out of 10). However, the experts clearly differentiate the demand by market segments, expecting an increasing demand of the gourmet market ( 8.1 out of 10), considering less relevant the organic $(4.6 \pm 1.0)$ and the proximity $(4.1 \pm 2.7)$ market. Other identified opportunities also obtained a relevant mark in spite of not been top ranked. The newly irrigated areas available for truffle cultivation (mainly in Spain) or the development of quality branding for the consumers to better identify the product obtained a mark of 7.9 and 7.4, respectively. On the other hand, other opportunities have not been considered as relevant as these. Among them, the potential for cultivation of other Tuber species (6.7 out of 10), with a 
poor mark in the case of T. brumale cultivation (3.6 out of 10), and the innovation with new truffle-based products (6.4 out of 10) (Table S3).

Table 2. Top five ranked strengths, weaknesses, opportunities, and threats identified by the truffle expert panel at the end of the second round.

\begin{tabular}{|c|c|c|}
\hline Statement & Mark (SD) (0-10) ${ }^{1}$ & SWOT Category \\
\hline $\begin{array}{c}\text { The truffle is characterized by a very passionate dimension also } \\
\text { providing additional incomes }\end{array}$ & $9.1(0.8)$ & Strengths \\
\hline $\begin{array}{c}\text { Truffles are very unique products, appreciated for their organoleptic } \\
\text { quality and highly appreciated in gastronomy }\end{array}$ & $9.0(1.2)$ & Strengths \\
\hline Increasing awareness of the truffle possibilities in the culinary world & $8.8(0.6)$ & Strengths \\
\hline $\begin{array}{c}\text { There are strong business companies in the Mediterranean that are } \\
\text { leading the sector }\end{array}$ & $8.4(1.2)$ & Strengths \\
\hline $\begin{array}{l}\text { The cultivation of black truffles is compatible with environmental } \\
\text { conservation as it is easily adaptable to organic farming requisites }\end{array}$ & $8.2(1.5)$ & Strengths \\
\hline $\begin{array}{l}\text { Truffle growers have to contribute to the agricultural social security as } \\
\text { soon as they start the activity whereas the truffle production will only } \\
\text { take place after } 7 \text { years or so }\end{array}$ & $8.9(2.0)$ & Weaknesses \\
\hline $\begin{array}{c}\text { Consumers are not informed enough about truffles and truffle products } \\
\text { and their use in gastronomy }\end{array}$ & $8.6(2.0)$ & Weaknesses \\
\hline $\begin{array}{l}\text { In spite of associationism, the productive sector is atomized and } \\
\text { non-professional. There is an increase of local initiatives, but a lack of } \\
\text { cooperation for the development of greater scope projects }\end{array}$ & $8.4(1.4)$ & Weaknesses \\
\hline $\begin{array}{l}\text { Imprecise management techniques (i.e., irrigation management, weed } \\
\text { control, fertilization, pruning) for truffle cultivation }\end{array}$ & $8.2(0.7)$ & Weaknesses \\
\hline $\begin{array}{l}\text { The return-on-investment period is long for black truffle plantations (in } \\
\text { comparison with other agricultural products) }\end{array}$ & $7.9(2.0)$ & Weaknesses \\
\hline Big potential for truffle-associated touristic and gastronomic activities & $8.9(1.0)$ & Opportunities \\
\hline Mediterranean countries still have high potential for truffle cultivation & $8.4(1.1)$ & Opportunities \\
\hline $\begin{array}{l}\text { Integration of the truffle with other products with high rural values } \\
\text { that will be attractive for luxury tourism ("terroir" concept) in several } \\
\text { regions }\end{array}$ & $8.4(1.2)$ & Opportunities \\
\hline Markets are still demanding more truffles, both fresh and processed & $8.3(1.1)$ & Opportunities \\
\hline $\begin{array}{l}\text { Increasing market trend of high quality, organic and proximity } \\
\text { products (three of the main features of the truffles) }\end{array}$ & $8.0(1.2)$ & Opportunities \\
\hline $\begin{array}{c}\text { Present pandemic and future global events might create economic } \\
\text { crises in tourism sector }\end{array}$ & $9.3(0.9)$ & Threats \\
\hline $\begin{array}{l}\text { Use of phytosanitary products in truffle cultivation is altering the } \\
\text { image of an organic product }\end{array}$ & $8.9(1.9)$ & Threats \\
\hline Large disturbance such as mega-fires could affect the truffle yields & $8.2(1.9)$ & Threats \\
\hline $\begin{array}{l}\text { Increase of wild boar populations threats mostly wild truffle } \\
\text { populations (in spite of their ecological role of spreading spores) }\end{array}$ & $8.1(1.7)$ & Threats \\
\hline $\begin{array}{c}\text { The chemical additives used as "truffle flavoring" in second tier } \\
\text { restaurants decreases truffles' prestige }\end{array}$ & $7.7(3.0)$ & Threats \\
\hline
\end{tabular}

${ }^{1}$ The mark ranges between 0 , non-relevant to 10, highly relevant. SD: standard deviation. The full list of strengths, weaknesses, opportunities, and threats with the correspondent marks can be found in Tables S1-S4.

The truffle sector identifies large disturbances, such as mega-fires (8.2 out of 10) or unexpected global events (i.e., pandemics) (9.3 out of 10), as potential threats for the sector, which is highly sensitive to the economic crises affecting tourism and gastronomy-related activities (Table 2). The local disturbances in wild and cultivated truffle beds caused by the 
increasing wild boar populations (8.1 out of 10) also worried the truffle operators. The use of phytosanitary products in truffle cultivation, which can affect the image of the truffle as an organic product, and the use of chemical additives used as "truffle flavoring" are also considered among the top ranked threats ( 8.9 and 7.6 out 10, respectively). In this last identified threat, some experts suggested the need to have a legal requirement at the EU level that request a minimum amount of truffle in truffle-labelled products (9.0 out of 10). Table S4 lists other threats that, in spite of not having been scored at the top of the ranking, are relevant for the sector, at least in certain areas. This is the case of the increase of land price in suitable areas for truffle cultivation (7.5 out of 10), the observed decrease of black truffle production due to climate change (7.4 out of 10), or the fact that several supply chain players are still operating outside the law (7.2 out of 10). The potential impact of pests and diseases that can affect truffle plantations is perceived as a very relevant threat to the sector in Spain (7.9 out of 10), but not in France (5.5 out of 10), Italy (4.0 out of 10), or Greece (2.0 out of 10) (Table S4).

\subsection{Challenges of the Truffle Sector}

The challenges of the sector vary with the position in the supply chain, namely production/harvesting, transformation, and commercialization (Table 3). The experts agreed that one of the most relevant challenges in truffle production ( 8.9 out of 10) is to guarantee the quality of the truffle-inoculated seedlings by promoting common certification procedures. The increase of the size of plantations implies the need for increasing mechanization of truffle farms (7.9 out of 10), parallel to the need for increasing research efforts in truffle plantations management (6.7 out of 10) (Table S5). The promotion of a Common Market Organization (CMO) for truffles (8.6 out of 10) raised to the top position of the transformation challenges for the expert panelists, who also agreed on the need to promote common quality standards ( 7.9 out of 10$)$, as well as the traceability of truffle products ( 7.7 out of 10), decreasing the presence artificial "truffle" flavors in truffle products (7.4 out of 10). In contrast, the truffle actors do not consider so relevant the need to guarantee the truffle chain of custody (4.0 out of 10) (Table S5).

Table 3. Top ranked challenges of the truffle sector identified by the truffle expert panel at the end of the second round (only marks higher than 7 have been included in the table).

\begin{tabular}{|c|c|c|}
\hline Challenge & Type of Challenge & Mark (SD) (0-10) ${ }^{1}$ \\
\hline $\begin{array}{l}\text { Common procedure for the certification of truffle-inoculated } \\
\text { seedlings (not only for T. melanosporum) }\end{array}$ & Production/harvesting & $8.9(0.9)$ \\
\hline The improvement of the mechanization of truffle farms & Production/harvesting & $7.9(2.0)$ \\
\hline $\begin{array}{l}\text { Promote the CMO (Common market organizations) for truffles } \\
\text { in Europe }\end{array}$ & Transformation & $8.6(1.6)$ \\
\hline Common Quality standards & Transformation & $7.9(1.6)$ \\
\hline Promote the traceability of truffle products & Transformation & $7.7(2.9)$ \\
\hline Promote the phasing out of artificial "truffle" flavors & Transformation & $7.4(2.3)$ \\
\hline $\begin{array}{l}\text { Increase of the communicative efforts focusing on countries } \\
\text { which do not have a tradition in truffle consumption }\end{array}$ & Commercialization & $8.9(0.8)$ \\
\hline Truffle tourism & Commercialization & $8.6(1.5)$ \\
\hline Traceability, labels, regional and cooperative brands & Commercialization & $7.7(1.9)$ \\
\hline Education, training, and awareness & Other challenges & $7.9(1.7)$ \\
\hline Minimize the fraud in truffle markets & Other challenges & $7.4(1.7)$ \\
\hline $\begin{array}{c}\text { Consolidation of the actor organizations, particularly the } \\
\text { producers by adequate means, before an inter-professional } \\
\text { integration }\end{array}$ & Other challenges & $7.3(0.9)$ \\
\hline
\end{tabular}

\footnotetext{
${ }^{1}$ The mark ranges between 0 , non-relevant to 10 , highly relevant. SD: standard deviation.
} 
The main challenge in truffle commercialization relies on the need to disseminate truffle products in countries without tradition in their consumption (8.9 out of 10). This challenge is in parallel with the idea of fostering truffle labels and regional or cooperative truffle brands (7.7 out of 10), and increasing the effort in education, training, and awareness (7.9 out of 10), not only for the consumers, but also for the truffle actors along the supply chain. The reduction of fraud in truffle markets (7.9 out of 10), the promotion of truffle tourism (8.6 out of 10), and the promotion of an interprofessional integration of the truffle actors ( 7.3 out of 10$)$ have been detected as relevant challenges that can also contribute to guarantee the resilience of the truffle sector.

\subsection{Actions to Develop the Truffle Sector and Guarantee Its Resilience}

The prioritized actions to be taken in order to reinforce the truffle sector derive from the sectorial analysis made by the expert panelists (Table 4). Those experts generally agreed on the strong values associated with truffle, which is perceived as an extraordinary product by consumers. This positive fact can support the idea of strengthening the link between truffles, tourism, and gastronomy (9.1 out of 10) as a disseminating driving force. This action can also be supported at European level with the recognition of truffle production (8.9 out of 10), homogenizing the international EU trade and taxation policies (8.9 out of $10)$, and promoting its consumption (8.1 out of 10). Other large-scale action that generated a high level of consensus within the panel is the need for promoting common protocols for the certification of mycorrhized seedlings ( 8.7 out of 10$)$. The truffle sector also needs to reinforce its internal capacities by increasing the training of the actors. In this sense, the promotion of tourism training for truffle farmers and the evaluation of the quality of fresh truffles and truffle products, both with a mark of 8.2 (out of 10), are examples of training actions to be promoted. Nevertheless, other actions, such as the improvement of the current legislations, seems to be country-dependent, having been highly rated in Spain (7.4 out of 10), rather than in Croatia, Italy, France, and Greece (with marks of 6.7, $6.3,6.1$, and 5.0 out of 10 , respectively). The domestication of new truffle species that can contribute to diversification of truffle product markets seems not to be a prioritized action in view of the low score obtained (3.5 out of 10) (Table S6).

Table 4. Top prioritized actions to be taken in the truffle sector identified by the truffle expert panel at the end of the second round (only marks higher than 8.5 have been included in the table).

\begin{tabular}{|c|c|}
\hline Prioritized Actions to Be Taken & Mark (SD) (0-10) ${ }^{1}$ \\
\hline Strengthen the link between truffles, tourism, and gastronomy & $9.1(0.9)$ \\
\hline Evaluate the role of truffles as important mycorrhizal symbionts in reforestation after large forest fires & $9.1(1.2)$ \\
\hline $\begin{array}{l}\text { Increase the effort at European level for the recognition of truffle production, helping to develop } \\
\text { truffle culture, and marketing }\end{array}$ & $8.9(1.2)$ \\
\hline Homogenize the international EU trade and taxation policies & $8.9(1.6)$ \\
\hline Develop a common protocol for the certification of the mycorrhized seedlings & $8.7(1.0)$ \\
\hline
\end{tabular}

${ }^{1}$ The mark ranges between 0 , non-relevant to 10 , highly relevant. SD: standard deviation.

\section{Discussion}

In this study, we described the truffle supply chain in the Mediterranean. The increasing economic activity generated by the truffle sector has promoted different activities related to the production and harvesting both in forests and in cultivated orchards. The activities related to the truffle sector have been expanded from selling fresh truffles to the transformation as an ingredient for several truffle products. Similarly, new activities such as truffle tourism as well as new commercialization channels, such as direct selling over the internet, are now part of the truffle economy map. These aspects are reflected in the truffle supply chain defined in this study by a consensus among panelists.

The experts agreed that truffles are a recognized gastronomic product with high growth potential (in both segments: fresh truffles, and truffle-based ingredients) in interna- 
tional markets, with the strongest companies leading the sector in the Mediterranean area. However, we have detected a certain concern about the evolution of prices. Cultivation has led to a substantial increase of black truffle in the market in a very short time, especially in Spain, and a certain fatigue in the prices paid to farmers has emerged in the last few seasons. Thus, there has been a price drop of 39\% and 33\% in the two most important markets in Spain and France, respectively, from 2015-2018 to 2018-2020. If we include the COVID-19 effect in the last season (2020-2021), the drop was $45 \%$ and $42 \%$ between 2015-2018 and 2018-2021 [35].

Truffle plantations are a highly profitable investment, which may be used by farmers to diversify and increase their benefits [36], with an internal rate of return (I.R.R.) over $9 \%[37,38]$. However, we showed the difficulties for new farmers to start this activity. This may be due to: (a) the long period to obtain a return on the investment, (b) the imprecise plantation management techniques for truffle cultivation due to basic information gaps in its biology and ecology, and (c) the atomized and not professionalized primary sector in some countries or regions. All this leads to Spain being the only country in this study where truffles are considered as a highly profitable crop. However, the potential to develop truffle cultivation in Mediterranean countries was considered as one of the most important opportunities for the truffle sector. In addition, we identified the opportunity of newly irrigated areas available for truffle cultivation, which is likely to have overcome concerns to consider a not-so-profitable crop perceived in France and Italy. The panel experts identified the following as challenges to develop truffle cultivation: the common procedure for the certification of truffle-inoculated seedlings and the improvement of mechanization of truffle farms. The quality of seedlings is one of the main factors that determine the success of a truffle orchard [39]. In fact, the truffle expert panel identified the development of a common protocol for certification of mycorrhized seedlings as a prioritized action to be taken to develop the truffle sector. On the other hand, the need for introducing mechanization in truffle plantations responds to the observed change of the truffle orchards' typology. As truffle farmers are becoming more professional, truffle culture is no longer a complementary activity and is becoming the exclusive economic activity for truffle farmers. The logical effect of this evolution is the increase in truffle plantation size, with consequent need of mechanizing the yearly truffle activities such as weed control, pruning, or the technique called "truffle nests" or "Spanish wells", consisting of an application of spores and peat in the soil to promote truffle fruiting [38,40,41].

The main threats shown in truffle cultivation were the use of phytosanitary products, mainly herbicides, which could undermine the image of a natural organic product. Yet there are currently alternatives to herbicides, such as mulches, with very positive results for the development of the mycelium of T. melanosporum in young truffle orchards [27,42-44]. The potential impact of pests and diseases affecting truffle plantations is perceived differently among countries, and it was considered an important threat for truffle cultivation only in Spain. This could be a consequence of the large continuous areas with this crop, which has caused the appearance of several pests and diseases [45], and the greater professionalization in the primary sector in Spain with respect to the other countries.

Contrary to expectations, the lack of continuing education focused on producers and technicians and the lack of technical support for truffle farmers have not been considered as the most relevant weaknesses. This could be due either to thinking that this demand is already met, or that it is useless because of the low quality of the training provided. It is also remarkable that the potential development of cultivation of other truffles is not considered a priority, varying depending on the truffle species. This fact is confirmed by the priority actions defined by the panelists, who do not consider as a priority the valuation or cultivation of truffle species other than T. melanosporum.

In the market, consumers are not sufficiently informed about the possibility to consume truffles and truffle products and their use in gastronomy. This could be explained by the fact that the consumption of truffles is relatively new in some countries, large year-to-year truffle production variability due to weather conditions, and its historical 
dependence on wild production, which cannot guarantee a stable annual supply. As a result, the industry has not planned to expand truffle marketing, never knowing if they would have enough product to sell. The increase and stabilization of production of black truffles thanks to cultivation, especially in Spain, is supporting marketing efforts. Tourism and gastronomy linked to production is a new opportunity to promote truffle consumption [46]. In fact, the truffle expert panel identified strengthening the link between truffles, tourism, and gastronomy as the most important action to be taken. Another aspect that could help in the promotion of truffles, is the development of the gourmet market, which can be complemented with quality branding to better identify the product.

Nevertheless, the present COVID-19 pandemic and future global events that might impact the tourism sector [26] must be taken into consideration when taking actions to promote truffle consumption. Developing a market, and local consumption of truffles, could help minimize such dependence on tourism. Another threat would be the use of synthetic aromas in the cuisine and in truffle products. These added aromas mask the original flavor and are more penetrating than the authentic truffle, giving consumers a confusing image about the real flavor of the black truffle [47]. According to the panelists, chemical substitutes of the truffle aroma should be fully discarded in the industry.

\section{Conclusions}

In this study, we conducted a Delphi survey through an expert panel that involved 17 actors of the truffle supply chain from five Mediterranean Europe countries. The results of our study describe the current truffle supply chain in the Mediterranean, realizing the maturity of such truffle supply chain due to the consolidation of T. melanosporum cultivation. The increase of truffle cultivation allows a steady production over time, encouraging the emergence of new companies specialized in the truffle market and consolidating the existing ones. We also observed important shifts in the roles that made up the traditional truffle supply chain operators, and as collectors that used to hunt in the wild and sell to small travelling buyers fade, hunters that collect for farmers and specialty wholesalers are emerging.

In the last few years, there have been concerns about price drops as cultivation increases. In this sense, the COVID-19 pandemic has brought an interesting lesson. Pandemic lockdown imposed the total closing of the restaurants with a consequent collapse of the price, however, the 2020-2021 truffle crop was completely sold, revealing the wide interest that the black truffle arouses in new private consumers. In spite of this positive data, as production increases, it will be necessary to promote truffle consumption. This will not be difficult, since the vast majority of the population is hardly aware that truffles are within their reach. In this study, we identified actions to develop the truffle sector, being the most important to: (a) strengthen the link between truffles, tourism, and gastronomy; (b) increase the effort at European level for the recognition of truffle production, helping to develop truffle culture and marketing; (c) increase the awareness and consumption of truffles among consumers; and (d) develop tourism workshops for truffle farmers.

Even though truffle cultivation is considered a profitable investment, we showed some difficulties in developing it in the countries studied, except in Spain, where it seems that black truffle cultivation is very consolidated and has a professionalized primary sector.

Supplementary Materials: The following are available online at https:/ / www.mdpi.com/article/ 10.3390/f12091174/s1, Table S1: Strengths identified by the truffle experts in the SWOT analysis of the truffle sector, Table S2: Weaknesses identified by the truffle experts in the SWOT analysis of the truffle sector, Table S3: Opportunities identified by the truffle experts in the SWOT analysis of the truffle sector, Table S4: Threats identified by the truffle experts in the SWOT analysis of the truffle sector, Table S5: Top ranked challenges of the truffle sector identified by the truffle expert panel, Table S6: Actions to be taken by the truffle sector identified by the truffle expert panel. 
Author Contributions: Conceptualization, D.O., E.V., A.B., O.M., N.A., K.S., J.M.d.A. and J.A.B.; methodology, D.O., E.V. and J.A.B.; software, J.M.d.A.; formal analysis, J.A.B.; investigation, D.O. and J.A.B.; resources, J.A.B.; data curation, J.A.B.; writing-original draft preparation, D.O., C.C. and J.A.B.; writing-review and editing, E.V., A.B., O.M., N.A., K.S., J.M.d.A., C.C. and J.A.B.; supervision, J.A.B.; project administration, J.A.B.; funding acquisition, E.V., A.B., O.M., N.A., K.S. and J.A.B. All authors have read and agreed to the published version of the manuscript.

Funding: This work was funded by the 'Innovation Networks of Cork, Resins and Edibles in the Mediterranean basin' (INCREdible) project, financed by the European Commission's Horizon 2020 programme under grant agreement $\mathrm{N}^{\circ} 774632$.

Institutional Review Board Statement: Not applicable.

Informed Consent Statement: Not applicable.

Data Availability Statement: Data are available at: www.incredibleforest.net (accessed on 1 August 2021).

Acknowledgments: We give special thanks to all the expert panelists who contributed with their time and expertise to make this study possible. We also thank the 'Departament d'Acció Climàtica, Alimentació i Agenda Rural' of 'Generalitat de Catalunya' for support. D. Oliach received support from the 'Secretaria d'Universitats i Recerca del Departament d'Economia i Coneixement de la Generalitat de Catalunya' through the program 'Doctorats Industrials'.

Conflicts of Interest: The authors declare no conflict of interest. The funders had no role in the design of the study; in the collection, analyses, or interpretation of data; in the writing of the manuscript, or in the decision to publish the results.

\section{References}

1. Boa, E. Wild Edible Fungi: A Global Overview of Their Use and Importance to People; Non-Wood Forest Products, No. 17; Food and Agriculture Organization of the United Nations: Rome, Italy, 2004; ISBN 92-5-105157-7.

2. Peintner, U.; Schwarz, S.; Mešić, A.; Moreau, P.-A.; Moreno, G.; Saviuc, P. Mycophilic or Mycophobic? Legislation and Guidelines on Wild Mushroom Commerce Reveal Different Consumption Behaviour in European Countries. PLoS ONE 2013, 8, e63926.

3. Guerin-Laguette, A. Successes and challenges in the sustainable cultivation of edible mycorrhizal fungi-Furthering the dream. Mycoscience 2021, 62, 10-28. [CrossRef]

4. Brundret, M.; Bougher, N.; Dell, B.; Grove, T.; Malajczuk, N. Working with Mycorrhizas in Forestry and Agriculture; ACIAR Monograph 32; ACIAR: Canberra, Australia, 1996; ISBN 1863201815.

5. Bonito, G.M.; Gryganskyi, A.P.; Trappe, J.M.; Vilgalys, R. A global meta-analysis of Tuber ITS rDNA sequences: Species diversity, host associations and long-distance dispersal. Mol. Ecol. 2010, 19, 4994-5008.

6. Reyna, S.; Garcia-Barreda, S. Black truffle cultivation: A global reality. For. Syst. 2014, 23, 317-328. [CrossRef]

7. Benucci, G.M.N.; Gógán Csorbai, A.; Baciarelli-Falini, L.; Marozzi, G.; Suriano, E.; Sitta, N.; Donnini, D. Taxonomy, Biology and Ecology of Tuber macrosporum Vittad. and Tuber mesentericum Vittad. In True Truffle (Tuber spp.) in the World: Soil Ecology, Systematics and Biochemistry; Zambonelli, A., Iotti, M., Murat, C., Eds.; Springer International: Cham, Switzerland, 2016; pp. 69-86. ISBN 978-3-319-31434-1.

8. Bach, C.; Beacco, P.; Cammaletti, P.; Babel-Chen, Z.; Levesque, E.; Todesco, F.; Cotton, C.; Robin, B.; Murat, C. First production of Italian white truffle (Tuber magnatum Pico) ascocarps in an orchard outside its natural range distribution in France. Mycorrhiza 2021, 31, 383-388. [CrossRef]

9. Liu, B.; Fischer, C.; Bonet, J.A.; Olivera, A.; Inchusta, A.; Colinas, C. Pattern of Tuber melanosporum extramatrical mycelium expansion over a 20-year chronosequence in Quercus ilex-truffle orchards. Mycorrhiza 2014, 24 (Suppl. S1), S47-S54. [CrossRef]

10. Merényi, Z.; Varga, T.; Bratek, Z. Tuber brumale: A Controversial Tuber Species. In True Truffle (Tuber spp.) in the World: Soil Ecology, Systematics and Biochemistry; Zambonelli, A., Iotti, M., Murat, C., Eds.; Springer International: Cham, Switzerland, 2016; pp. 49-68. ISBN 978-3-319-31434-1.

11. Zambonelli, A.; Iotti, M.; Hall, I. Current status of truffle cultivation: Recent results and future perspectives. Micol. Ital. 2015, 44, 31-40.

12. Šiškovič, N.; Strojnik, L.; Grebenc, T.; Vidrih, R.; Ogrinc, N. Differentiation between species and regional origin of fresh and freeze-dried truffles according to their volatile profiles. Food Control 2021, 123, 107698. [CrossRef]

13. Riccioni, C.; Rubini, A.; Belfiori, B.; Gregori, G.; Paolocci, F. Tuber magnatum: The special one. What makes it so different from the other Tuber spp.? In True Truffle (Tuber spp.) in the World: Soil Ecology, Systematics and Biochemistry; Zambonelli, A., Iotti, M., Murat, C., Eds.; Springer International: Cham, Switzerland, 2016; pp. 87-103. ISBN 978-3-319-31434-1.

14. Oliach, D.; Morte, A.; Sánchez, S.; Navarro-Ródenas, A.; Marco, P.; Gutiérrez, A.; Martín-Santafé, M.; Fischer, C.; Albisu, L.M.; García-Barreda, S.; et al. Las trufas y las turmas. In Los Productos Forestales No Madereros en España: Del Monte a la Industria; Sánchez-González, M., Calama, R., Bonet, J.A., Eds.; INIA, Ministerio de Ciencia e Innovación; Gobierno de España: Madrid, Spain, 2020; pp. 283-324. ISBN 978-84-7498-585-6. 
15. Molinier, V.; Peter, M.; Stobbe, U.; Egli, S. The Burgundy truffle (Tuber aestivum syn. uncinatum): A truffle species with a wide habitat range over Europe. In True Truffle (Tuber spp.) in the World: Soil Ecology, Systematics and Biochemistry; Zambonelli, A., Iotti, M., Murat, C., Eds.; Springer International: Cham, Switzerland, 2016; pp. 33-47. ISBN 978-3-319-31434-1.

16. Lancellotti, E.; Iotti, M.; Zambonelli, A.; Franceschini, A. The Puberulum Group Sensu Lato (Whitish Truffles). In True Truffle (Tuber spp.) in the World: Soil Ecology, Systematics and Biochemistry; Zambonelli, A., Iotti, M., Murat, C., Eds.; Springer International: Cham, Switzerland, 2016; pp. 105-124.

17. De Roman, M.; Boa, E. Collection, marketing and cultivation of edible fungi in Spain. Micol. Apl. Int. 2004, 16, 25-33.

18. Büntgen, U.; Latorre, J.; Egli, S.; Martínez-Peña, F. Socio-economic, scientific, and political benefits of mycotourism. Ecosphere 2017, 8, e01870. [CrossRef]

19. Murat, C. Forty years of inoculating seedlings with truffle fungi: Past and future perspectives. Mycorrhiza 2014, $25,77-81$. [CrossRef]

20. Le Tacon, F.; Marçais, B.; Courvoisier, M.; Murat, C.; Montpied, P.; Becker, M. Climatic variations explain annual fluctuations in French Périgord black truffle wholesale markets but do not explain the decrease in black truffle production over the last 48 years. Mycorrhiza 2014, 24, S115-S125. [CrossRef] [PubMed]

21. Büntgen, U.; Egli, S.; Camarero, J.J.; Fischer, E.M.; Stobbe, U.; Kauserud, H.; Tegel, W.; Sproll, L.; Stenseth, N.C. Drought-induced decline in Mediterranean truffle harvest. Nat. Clim. Chang. 2012, 2, 827-829. [CrossRef]

22. Thomas, P.; Büntgen, U. A risk assessment of Europe's black truffle sector under predicted climate change. Sci. Total Environ. 2019, 655, 27-34. [CrossRef] [PubMed]

23. Federación Española de Asociaciones de Truficultores (FETT); Sarrión, Spain. Personal communication, 2021.

24. Čejka, T.; Trnka, M.; Krusic, P.J.; Stobbe, U.; Oliach, D.; Václavík, T.; Tegel, W.; Büntgen, U. Predicted climate change will increase the truffle cultivation potential in central Europe. Sci. Rep. 2020, 10, 21281. [CrossRef] [PubMed]

25. Ramírez, R.; (Agritufas SpA, Talca, Chile). Personal communication, 2021.

26. Čejka, T.; Isaac, E.; Oliach, D.; Martínez-Peña, F.; Egli, S.; Thomas, P.; Trnka, M.; Büntgen, U. Risk and reward of the emerging truffle sector under predicted global climate change. Environ. Res. Lett. 2021. submitted for publication.

27. Oliach, D.; Colinas, C.; Castaño, C.; Fischer, C.R.; Bolaño, F.; Bonet, J.A.; Oliva, J. The influence of forest surroundings on the soil fungal community of black truffle (Tuber melanosporum) plantations. For. Ecol. Manag. 2020, 469, 118199. [CrossRef]

28. Masiero, M.; Pettenella, D.; Secco, L. From failure to value: Economic valuation for a selected set of products and services from Mediterranean forests. For. Syst. 2016, 25, e051. [CrossRef]

29. Lovrić, M.; Da Re, R.; Vidale, E.; Prokofieva, I.; Wong, J.; Pettenella, D.; Verkerk, P.J.; Mavsar, R. Non-wood forest products in Europe-A quantitative overview. For. Policy Econ. 2020, 116, 102175. [CrossRef]

30. Lovrić, M.; Da Re, R.; Vidale, E.; Pettenella, D.; Mavsar, R. Social network analysis as a tool for the analysis of international trade of wood and non-wood forest products. For. Policy Econ. 2018, 86, 45-66. [CrossRef]

31. Samils, N.; Olivera, A.; Danell, E.; Alexander, S.J.; Fischer, C.; Colinas, C. The Socioeconomic Impact of Truffle Cultivation in Rural Spain. Econ. Bot. 2008, 62, 331-340. [CrossRef]

32. Büntgen, U.; Egli, S. Breaking new ground at the interface of dendroecology and mycology. Trends Plant Sci. 2014, 19, 613-614. [CrossRef]

33. Rowe, G.; Wright, G. Expert opinions in forecasting: The role of the Delphi technique. In Principles of Forecasting: A Handbook for Researchers and Practitioners; Armstrong, J.S., Ed.; Kluwer Academic Publishers: Boston, MA, USA, 2001; pp. 125-144.

34. Green, K.C.; Armstrong, J.C.; Graefe, A. Methods to Elicit Forecasts from Groups: Delphi and Prediction Markets Compared. Int. J. Appl. Forecast. 2007, 8, 17-20.

35. Truffle Prices. Available online: http:/ / www.observatoriforestal.cat/preus-de-la-tofona/ (accessed on 7 June 2021).

36. Bonet, J.A.; Oliach, D.; Fischer, C.; Olivera, A.; de Aragon, J.M.; Colinas, C. Cultivation Methods of the Black Truffle, the Most Profitable Mediterranean Non-Wood Forest Product; A State of the Art Review. In Proceedings of the Modelling, Valuing and Managing Mediterranean Forest Ecosystems for Non-Timber Goods and Services, Palencia, Spain, 26-27 October 2007; Palahí, M., Birot, Y., Bravo, F., Gorriz, E., Eds.; European Forest Institute Proceedings No. 57. European Forest Institute: Joensuu, Finland, 2009; pp. 57-71.

37. Bonet, J.A.; Colinas, C. Cultivo de Tuber melanosporum Vitt. Condiciones y rentabilidad. Forestalia 2001, 5, 38-45.

38. Fischer, C.; Oliach, D.; Bonet, J.A.; Colinas, C. Best Practices for Cultivation of Truffles; Forest Sciences Centre of Catalonia (CTFC): Solsona, Spain; Yaşama Dair Vakıf: Antalaya, Turkey, 2017; ISBN 978-84-697-8163-0.

39. Andrés-Alpuente, A.; Sánchez, S.; Martín, M.; Aguirre, A.J.; Barriuso, J.J. Comparative analysis of different methods for evaluating quality of Quercus ilex seedlings inoculated with Tuber melanosporum. Mycorrhiza 2014, 24 (Suppl. S1), S29-S37. [CrossRef] [PubMed]

40. Murat, C.; Bonneau, L.; De la Varga, H.; Olivier, J.-M.; Sandrine, F.; Tacon, F. Trapping truffle production in holes: A promising technique for improving production and unravelling truffle life cycle. Ital. J. Mycol. 2016, 45, 47-53.

41. Garcia-Barreda, S.; Marco, P.; Martín-Santafé, M.; Tejedor-Calvo, E.; Sánchez, S. Edaphic and temporal patterns of Tuber melanosporum fruitbody traits and effect of localised peat-based amendment. Sci. Rep. 2020, 10, 4422. [CrossRef]

42. Olivera, A.; Bonet, J.A.; Palacio, L.; Liu, B.; Colinas, C. Weed control modifies Tuber melanosporum mycelial expansion in young oak plantations. Ann. For. Sci. 2014, 71, 495-504. [CrossRef] 
43. Piñuela, Y.; Alday, J.G.; Oliach, D.; Castaño, C.; Bolaño, F.; Colinas, C.; Bonet, J.A. White mulch and irrigation increase black truffle soil mycelium when competing with summer truffle in young truffle orchards. Mycorrhiza 2021, 31, 371-382. [CrossRef]

44. Şen, İ.; Piñuela, Y.; Alday, J.G.; Oliach, D.; Bolaño, F.; Martínez de Aragón, J.; Colinas, C.; Bonet, J.A. Mulch removal time did not have significant effects on Tuber melanosporum mycelium biomass. For. Syst. 2021, 30, eSC02. [CrossRef]

45. Martín-Santafé, M.; Pérez-Fortea, V.; Zuriaga, P.; Barriuso-Vargas, J. Phytosanitary problems detected in black truffle cultivation. A review. For. Syst. 2014, 23, 307. [CrossRef]

46. Latorre, J.; De-Magistris, T.; de Frutos, P.; García, B.; Martinez-Peña, F. Demand for mycotourism products in rural forest areas. A choice model approach. Tour. Recreat. Res. 2021. [CrossRef]

47. Campo, E.; Guillén, S.; Marco, P.; Antolín, A.; Sánchez, C.; Oria, R.; Blanco, D. Aroma composition of commercial truffle flavoured oils: Does it really smell like truffle? In Proceedings of the Acta Horticulturae, Cartagena, Murcia, 21-24 June 2016; International Society for Horticultural Science (ISHS): Leuven, Belgium, 2018; pp. 1133-1140. 